\title{
Knowledge and behavioral patterns of youth ice hockey parents regarding sport concussion: a pilot study
}

\author{
Jeff G. Konin \\ University of Rhode Island, jeffkonin@hotmail.com \\ Delaney Horsley
}

Follow this and additional works at: https://nsuworks.nova.edu/ijahsp

Part of the Health Communication Commons, Physical Therapy Commons, Sports Medicine Commons, and the Sports Sciences Commons

This Manuscript has supplementary content. View the full record on NSUWorks here: https://nsuworks.nova.edu/ijahsp/vol15/iss2/2

\section{Recommended Citation}

Konin JG, Horsley D. Knowledge and behavioral patterns of youth ice hockey parents regarding sport concussion: a pilot study. The Internet Journal of Allied Health Sciences and Practice. 2017 Jan 01;15(2), Article 2.

This Manuscript is brought to you for free and open access by the College of Health Care Sciences at NSUWorks. It has been accepted for inclusion in Internet Journal of Allied Health Sciences and Practice by an authorized editor of NSUWorks. For more information, please contact nsuworks@nova.edu. 


\title{
Knowledge and behavioral patterns of youth ice hockey parents regarding sport concussion: a pilot study
}

\begin{abstract}
Purpose: There is an abundance of available concussion education programs for parents of youth ice hockey players. Parents play a vital role in recognizing signs and symptoms of a concussion sustained by a child, and therefore their knowledge and retention of such information is deemed to be very important. The purpose of the pilot survey is identify the general knowledge parents of youth ice hockey players possess regarding concussion. Methods: A survey of a sample of convenience was utilized. Forty-five parents (40 to 49 years of age) of youth ice hockey players were asked to complete a one-page survey to assess their knowledge of concussion. The ages of their children ranged from seven through ten, and all parents were recruited to participate while attending a team practice session at a local ice hockey arena. Results: Parents generally were aware of common concussion related symptoms (headache $98 \%$, difficulty with concentrating $96 \%$, mental confusion $91 \%$, vomiting $91 \%$, sensitivity to light $91 \%$, and blurred vision $82 \%$ ) while not so familiar with symptoms such as tinnitus (62\%) and agitated behaviors (47\%). Fifty percent of those surveyed were unaware if their youth hockey organization had a concussion policy. Conclusion: Parents of youth ice hockey players seem to fail to retain information learned from concussion education programs. Barriers to learning retention may include the ages of the youth participating, the abundance of informal and inconsistent information that is available, and the lack of organizational administration of concussion education programs. Parents appear to be receptive to receiving more information regarding the safety of their children. Parental recognition of the signs and symptoms of a concussion sustained while playing youth ice hockey may lead to more appropriate and timely management of the injury.
\end{abstract}

\section{Author Bio(s)}

Jeff G. Konin, PhD, PT, ATC, FACSM, FNATA, is a Professor and Chair of the Physical Therapy Department at the University of Rhode Island.

Delaney Horsley is affiliated with the Kinesiology Department at the University of Rhode Island. 


\title{
IUAHSP \\ The Internet Joưnal of Allied Health Sciences and Practice
}

Dedicated to allied health professional practice and education

Vol. 15 No. 2 ISSN 1540-580X

\section{Knowledge and Behavioral Patterns of Youth Ice Hockey Parents Regarding Sport Concussion: A Pilot Study}

\author{
Jeff G. Konin, PhD \\ University of Rhode Island \\ United States
}

\begin{abstract}
Purpose: There is an abundance of available concussion education programs for parents of youth ice hockey players. Parents play a vital role in recognizing signs and symptoms of a concussion sustained by a child, and therefore their knowledge and retention of such information is deemed to be very important. The purpose of the pilot survey is identify the general knowledge parents of youth ice hockey players possess regarding concussion. Methods: A survey of a sample of convenience was utilized. Forty-five parents ( 40 to 49 years of age) of youth ice hockey players were asked to complete a one-page survey to assess their knowledge of concussion. The ages of their children ranged from seven through ten, and all parents were recruited to participate while attending a team practice session at a local ice hockey arena. Results: Parents generally were aware of common concussion related symptoms (headache $98 \%$, difficulty with concentrating $96 \%$, mental confusion $91 \%$, vomiting $91 \%$, sensitivity to light $91 \%$, and blurred vision $82 \%$ ) while not so familiar with symptoms such as tinnitus (62\%) and agitated behaviors (47\%). Fifty percent of those surveyed were unaware if their youth hockey organization had a concussion policy. Conclusion: Parents of youth ice hockey players seem to fail to retain information learned from concussion education programs. Barriers to learning retention may include the ages of the youth participating, the abundance of informal and inconsistent information that is available, and the lack of organizational administration of concussion education programs. Parents appear to be receptive to receiving more information regarding the safety of their children. Parental recognition of the signs and symptoms of a concussion sustained while playing youth ice hockey may lead to more appropriate and timely management of the injury.
\end{abstract}

\section{INTRODUCTION}

It is estimated that more than 3 million sports-related concussions occur annually in the United States, with some 300,000 prevalent in the secondary school setting. ${ }^{1}$ Specifically, ice hockey is one of the sports with the greatest number of reported concussions. ${ }^{2,3}$ In 2012, The 4th International Conference on Concussion in Sport held in Zurich defined a concussion as "a complex pathophysiologic process affecting the brain induced by traumatic biomechanical forces." ${ }^{3,4}$ This definition has served as consistent standardized terminology for all healthcare providers to follow.

Healthcare providers have acquired an informal responsibility to convey concussion prevention, recognition, and management information to parents, coaches, and student athletes. Such intent is primarily educational in nature, yet likely is designed to implement behavioral change through knowledge transfer. To date, various methods have been used to educate stakeholders with a greater risk of being associated with a sports-related concussion. These methods have included live educational presentations to teams and organizations, on-line tutorial courses, and a plethora of available printed resources. Modes of delivery vary and requirements vary, with concussion education programs offered voluntarily, mandated through organizations, and mandated through legislation passed within each state. ${ }^{1,5}$

The first concussion legislation was enacted in Washington State, which required the delivery of education to coaches, parents, and athletes. Recent findings from this required implementation have suggested that knowledge transfer has not been as effective for parents. ${ }^{5}$ More specifically, retention of concussion education in a specific population of ice hockey players through the use of educational videos has been shown to be transient, with decreased retention found within 2 months of delivery. ${ }^{6}$ Kroshus et al have noted the impact of education may result in an under-reporting of symptoms. ${ }^{7}$ It is believed that this occurs 
from athletes, and perhaps parents, not wanting a removal from sport participation, and therefore not informing coaches, officials, or medical providers of signs or symptoms that one may be experiencing. Additionally, Kurowski et al note that concussion education programs have had minimal benefits with respect to changing the culture of reporting concussion-related symptoms with athletes ages 13 to 18 participating in high risk sports. ${ }^{16}$ Furthermore, it has been suggested that concussion education programs mandated through legislation have not resulted in cultural changes in sports designed to better protect athletes, other forms of education should focus on improving attitudes and beliefs of parents to promote better care-seeking behaviors. ${ }^{8-11}$ Other studies have shown that the ability to effectively transfer knowledge related to concussion education has been influenced by such factors as socioeconomic status and one's primary spoken and written language. ${ }^{12}$ Such circumstances and classes may lend themselves to a decrease to access and comprehension of available concussion educational materials.

The purpose of this study was to determine the knowledge of parents of youth ice players regarding concussion. It was hypothesized that based upon the abundance of concussion education programs available and the amount of recent public attention of recent regarding sports concussion, parents of youth ice hockey players would be knowledgeable regarding basic recognition of concussion signs and symptoms.

\section{Methods}

Surveys were distributed to a sample of convenience with the intent of conducting a descriptive, quantitative research design. The study was approved by the University of Rhode Island's Institutional Review Board. The authors of the study attended practice sessions of a local youth ice hockey association and invited parents in attendance to participate in a questionnaire consisting of a total of twelve questions (Figure 1). Informed consent was obtained and the study's investigator was readily available to clarify any questions on the survey.

\section{Figure 1. Survey administered to participants.}

1. Your gender is
a. Male
b. Female

2. Your age group is
a. $20-29$
b. $30-39$
c. $40-49$
d. $50-59$
e. $>59$

3. Does your team employ or have a volunteer professional healthcare provider who is present at practices or games? (If no, skip question \# 4)
a. Yes
b. No

4. The healthcare provider is a
a. Certified Athletic Trainer
b. School Nurse
c. Physical Therapist
d. EMT/Paramedic
e. Medical Doctor
f. Chiropractor
g. Neuropsychologist
h. Other (Please List) 
5. Does your hockey program have a policy on assessing and managing an athlete who has sustained a concussion?
a. Yes
b. No
c. I am not sure

6. Have you ever been in a position as a parent where you were asked to assist in making a decision regarding a player on the youth ice hockey team who sustained a concussion? This could include assessing the concussion and/or determining if the athlete could continue playing.
a. Yes
b. No

7. How long do you think that an athlete should typically be held out from ice hockey participation after sustaining a concussion?
a. 1 day
b. 2-3 days
c. 3-7 days
d. 1-2 weeks
e. $>2$ weeks
f. Remainder of season
g. Varies based on each concussion

8. Please place an "X" in the space to the left of the symptoms listed in the table below that you would agree are associated with an athlete that has sustained a concussion.

Example:

___ double vision

$\begin{array}{ll} & \text { Headache } \\ & \text { Difficulty concentrating } \\ \text { Clenching fist } \\ \text { More emotional } \\ \text { Sensitivity to light } \\ \text { Sleeping more than usual } \\ \text { Double vision } \\ \text { Irritability } \\ \text { Mental slowness } \\ \text { Difficulty sleeping } \\ \text { Visual problems } \\ \text { Agitation } \\ \text { Intermittent foot pain } \\ \text { Trouble finding words } \\ \text { Numbness/tingling } \\ \text { Mental confusion } \\ \text { Vomiting } \\ \text { Ringing in the ears } \\ \text { Drowsiness }\end{array}$


10. Have you heard of computer programs to help determine if an athlete sustained a concussion?

a. Yes

If yes, please list the program(s) that you have heard of:

Name of program(s):

b. No

11. Are computer-testing programs currently used by your hockey program to test for concussions?
a. Yes
b. No

12. Please indicate the personnel, programs, or equipment that you currently do not have, but would like to assist you in the diagnosis and management of concussion in student athletes.

Certified Athletic Trainer
School Nurse
Physical Therapist
Medical Doctor
Chiropractor
Neuropsychologist
EMT/Paramedic
Computerized testing programs to identify symptoms of concussion
New and improved helmets protecting against concussion
Mouth Guards that protect against concussion
Teaching seminars for coaches

Please feel free to share any additional thoughts or comments you may have:

\section{Results}

Forty-five parents participated and completed the survey in its entirety. Participants ranged in age from 40 to 47 (average age $42.5,58 \%$ males \& $42 \%$ females). Overall, nearly half of the parents were not sure if their youth ice hockey program had a policy on assessing or managing an athlete who had sustained a concussion. The majority of parents were able to identify the most obvious of concussion symptoms such as headache, difficulty concentrating, sensitivity to light, mental confusion, and vomiting. 
Nearly half of the parents were able to identify less common symptoms such as becoming more emotional, showing more signs of irritability, and having difficulty sleeping. Five parents wrongly identified clenching of the fist and intermittent foot pain as concussion symptoms. Approximately two-thirds of the parents surveyed had not heard of neurocognitive-based computer software programs as part of the concussion assessment process (Table 1).

Parents noted increased staffing (Certified athletic trainer), better designed mouth guards, and concussion education programs as interventions they would like to see implemented in their youth ice hockey program in an effort to enhance in the diagnosis and management of sustained concussions.

\section{Discussion}

The results of the surveys only partially supported our hypothesis that parents of youth ice hockey players would be knowledgeable regarding basic recognition of concussion signs and symptoms. Of most interest was the simple fact that $47 \%$ of the respondents were unaware whether or not their youth ice hockey organization had an existing policy in place regarding concussions. Forty-seven percent of the respondents stated that a policy did exist. In fact, for this particular organization, no policy exists and no educational training is required for coaches or parents. While this represents an area lacking within the organization itself, the outcome results in a deficiency of parental knowledge of how to recognize and manage concussions sustained by their children. It is unclear how these findings would compare to other similar youth ice hockey organizations within the same or different geographical regions.

The overwhelming majority of parents were aware that there is no type of onsite healthcare coverage at their child's ice hockey events. A small percentage (11\%) thought that an EMT was onsite for game coverage. When asked about the personnel that they would like to have present at youth ice hockey games, parents preferred certified athletic trainers (47\%), physicians (24\%), and EMT/paramedics (20\%). Respondents also noted their interest in having school nurses, physical therapists, and neuropsychologists involved in the assistance of diagnosing and managing concussions.

Independent organizations and communities manage sport-related concussion differently despite efforts to establish standards of care. For example, a recent survey of physical therapists demonstrated a self-reported lack of confidence when making return to play decisions following a concussion sustained by a youth athlete. With proper training, physical therapists are qualified to make such decisions and in fact legally supported to do so by legislation in some states. ${ }^{5}$ Published evidence was not found to suggest that all school nurses possess the necessary qualifications to assess and manage sport-related concussion. ${ }^{13}$ Echlin et al found that with university level ice hockey players, a 3-5x higher rate of reported concussion-like symptoms was found when a physician was actually present to observe the games. ${ }^{3}$ This supports previous studies that have noted an underreporting of symptoms to coaches and parents alike despite having adequate knowledge of common signs and symptoms of a potentially sustained sport-related concussion. $8,10,14 \mathrm{~A}$ small percentage of the respondents $(20 \%)$ noted that they have been in a position as a parent to assist in making a decision regarding a player on a youth ice hockey team who sustained a concussion. Work remains to be done to establish standardized sport and venue specific on-site management of sport concussions; current findings reveal that such standards are left to each organization to establish.

The lack of a concussion policy within the organization and more importantly the lack of any form of education training for parents were not necessarily evident in the responses regarding recognition of concussion signs and symptoms. The majority of the respondents successfully recognized common signs and symptoms of a concussion such as headache (98\%), difficulty concentrating $(96 \%)$, mental confusion $(91 \%)$, vomiting $(91 \%)$, drowsiness $(78 \%)$, sleep disturbances $(73 \%)$, visual changes $(71 \%)$, language disturbance $(67 \%)$, and tinnitus $(62 \%)$. Parents were less cognizant of agitation and irritability (47\%) being associated with post-concussive symptoms, and some parents misidentified a clenching fist $(11 \%)$ and intermittent foot pain $(11 \%)$ as symptoms associated with a concussion. Overall, responses reflected a general awareness of parental knowledge that a concussion should be suspected with emotional and physical signs and symptoms that are not normally present in a child.

Concussions are currently managed with a graduated return to participation protocol, with no specific set timetable for each individual to return to sport. ${ }^{4}$ Parents were asked how many days they thought a child with a concussion should refrain from participating in ice hockey, and most (67\%) responded accurately noting it would entirely depend on the individual circumstance. Some parents believed a pre-established timeline is set for return to play: > 2 weeks (12\%), 1-2 weeks (11\%), 3-7 days (6\%), and 2-3 days (4\%). There appears to continue to be some lack of knowledge transfer regarding the individualism of each sustained concussion and the time it takes for recovery and return to participation. Continued education regarding the lack of "concussion rating" (mild/moderate/severe, $1{ }^{\circ} / 2^{\circ} / 3^{\circ}$ ) and the importance of a symptom-based assessment should be emphasized in all education programs delivered to parents, coaches, and athletes. ${ }^{14}$

(c) The Internet Journal of Allied Health Sciences and Practice, 2017 
Overall, parents were supportive of efforts designed to increased their awareness and knowledge of sport-related concussion for children who play ice hockey. Approximately half of the respondents believed that coaches (53\%), parents (47\%), and youth athletes $(42 \%)$ should receive concussion education. Despite research that demonstrates limited retention from educational programs, this is a positive finding. $6,15,16$ Only a small percentage (29\%) of respondents were aware of computer-based testing programs used for baseline assessment of cognitive function, a component of current suggested guidelines for concussion assessment and management. ${ }^{4}$ While such neurocognitive tests are not available to each athlete/parent, and furthermore may also be limited as a resource due to socioeconomic or language barriers, they can serve as a valuable tool for establishing baseline cognitive status and assessment of regression/progression following a head injury. Interestingly, parents felt that new and improved helmets (47\%) and mouth guards (47\%) would be helpful despite clear evidence that neither is designed to prevent or minimize the risk and severity of sport-related concussions. ${ }^{4}$

This pilot work should be interpreted only within the context of its findings, and not translated to reflect all other youth ice hockey organizations. Participants from this study were conveniently selected from a small sample of local parents from with a single youth ice hockey organization. However, while it may not be appropriate to use the findings of this study as a broader representation of all youth ice hockey programs and parent's knowledge of sport-related concussion, this pilot study may in fact be reflective of other findings of larger samples and should be considered a possibility of what one would find in his or her local or regional program.

A potential limitation of this study realized after the survey was administered is the fact that the children of the parents surveyed were primarily of the ages between 7 and 10. Youth ice hockey players of this age do not participate in checking as part of their practices and games. Since checking is not permitted at these ages, it is possible that surveying parents within an organization that does in fact have a concussion policy with an educational component may still yield similar findings since such a program may be geared toward children and parents of an older age group where checking is permitted. Regardless, it is the opinion of the authors of this study that concussion education should in fact begin at younger ages since overall knowledge transfer appears to be less than optimal. Perhaps, for example, repetitive annual education programs will lead to a greater retention of concussion knowledge.

\section{Conclusion}

The findings of this pilot survey demonstrate that parents of youth ice hockey players have a general knowledge of sportconcussion related signs and symptoms, yet would benefit from increased education that could potentially lead to more knowledge transfer. Parents are supportive of education programs that also promote knowledge for coaches and children. Future surveys should consider a larger, more diverse sample across youth ice hockey organizations.

\section{References}

1. Kay MC, Welch CE, Valovich McLeod TC. Positive and negative factors that influence concussion reporting among secondary-school athletes. J Sport Rehabil. 2015;24:210-3. [PMID: 24458373]

2. Echlin PS, Skopolja EN, Worsley R, Dadachanji SB, Lloyd-Smith DR, Taunton JA, Forwell LA, Johnson AM. A prospective study of physician-observed concussion during a varsity university ice hockey season: incidence and neuropsychological changes. Part 2 of 4. Neurosurg Focus. 2012;33(6):e2:1-11. [PMID: 23199425]

3. Zuckerman SL, Kerr ZY, Yengo-Kahn A, Wasserman E, Covassin T, Solomon GS. Epidemiology of sports-related concussion in NCAA athletes from 2009-2010 to 2013-2014: incidence, recurrence, and mechanisms. Am J Sports Med. 2015 Nov;43(11):2654-62. [PMID: 26330572]

4. McCrory P. Meeuwisse WH, Aubry M, et al. Consensus statement on concussion in sport: the 4th International Conference on Concussion in Sport held in Zurich, November 2012. PM R. 2013;5(4):255-79. [PMID: 23466418]

5. Chrisman SP, Schiff MA, Chung SK, Herring SA, Rivara FP. Implementation of concussion legislation and extent of concussion education for athletes, parents, and coaches in Washington State. Am J Sports Med. 2014 May;42(5):1190-6. [PMID: 24510067]

6. Cusimano MD, Chipman M, Donnelly P, Hutchison MG. Effectiveness of an educational video on concussion knowledge in minor league hockey players: a cluster randomised controlled trial. Br J Sports Med. 2014 Jan;48(2):1416. [PMID: 23918445]

7. Kroshus E, Kubzansky LD, Goldman RE, Austin SB. Norms, athletic identity, and concussion symptom under-reporting among male collegiate ice hockey players: a prospective cohort study. Ann Behav Med. 2015 Feb;49(1):95-103. [PMID: 25236670] 
8. O'Kane JW, Levy MR, Neradilek M, Polissar NL, Schiff MA. Evaluation of the Zachery Lystedt Law among female youth soccer players. Phys Sportsmed. 2014 Sep;42(3):39-44. [PMID: 25295765]

9. Register-Mihalik JK, Linnan LA, Marshall SW, Valovich McLeod TC, Mueller FO, Guskiewicz KM. Using theory to understand high school aged athletes' intentions to report sport-related concussion: implications for concussion education initiatives. Brain Inj. 2013;27(7-8):878-86. [PMID: 23789865]

10. Rivara FP, Schiff MA, Chrisman SP, Chung SK, Ellenbogen RG, Herring SA. The effect of coach education on reporting of concussions among high school athletes after passage of a concussion law. Am J Sports Med. 2014 May;42(5):1197-203. [PMID: 24569704]

11. Shenouda C, Hendrickson P, Davenport K, Barber J, Bell KR. The effects of concussion legislation one year later-what have we learned: a descriptive pilot survey of youth soccer player associates. PM R. 2012 Jun;4(6):427-35. [PMID: 22543038]

12. Jones NS, Walter KD, Caplinger R, Wright D, Raasch WG, Young C. Effect of education and language on baseline concussion screening tests in professional baseball players. Clin J Sport Med. 2014 Jul;24(4):284-8. [PMID: 24184854]

13. Yorke AM, Littleton S, Alsalaheen BA. Concussion attitudes and beliefs, knowledge, and clinical practice survey of physical therapists. Phys Ther. 2016;96(7):1018-28. [PMID: 26637654]

14. Noble J, Hesdorffer D. Sport-related concussions: a review of epidemiology, challenges in diagnosis, and potential risk factors. Neuropsychol Rev. 2013;23(4):273-84. [PMID: 24242889]

15. Kroshus E, Daneshvar DH, Baugh CM, Nowinski CJ, Cantu RC. NCAA concussion education in ice hockey: an ineffective mandate. Br J Sports Med. 2014 Jan;48(2):135-40. [PMID: 23956336]

16. Kurowski BG, Pomerantz WJ, Schaiper C, Ho M, Gittelman MA. Impact of preseason concussion education on knowledge, attitudes, and behaviors of high school athletes. J Trauma Acute Care Surg. 2015 Sep;79(3 Suppl 1):S218. [PMID: 26308118] 